\title{
Environmental Sustainability: Students' Ecological Footprints
}

\author{
Juanita M. Cruz \\ Systems Plus College Foundation \\ Angeles City, Philippines \\ juanitacruz2004@gmail.com
}

\begin{abstract}
The environmental problems globally threatening our survival cannot be ignored. This study was undertaken to measure and compare students' ecological footprints from three countries and to determine their awareness of the impact of these footprints on environmental sustainability. Ecological footprint measures the balance between demand on the Earth's natural resources and its capacity to supply these resources. It comprises a person's consumption of goods and services such as carbon, food, and housing. Students from Canada (15), Philippines (78) and Thailand (120) took the quiz online at myfootprint.org. ANOVA showed significant differences in the responses wherein Canadians and Thais consumed more resources than the Filipino students which can be traced to their higher economic levels and disposable incomes. Survey revealed that $40 \%$ felt glad knowing they help in ensuring ecological sustainability, $27 \%$ felt relieved their lifestyles are sustainable, $16 \%$ felt embarrassed for consuming more resources than what the Earth can provide, $14 \%$ were concerned but cannot change their lifestyles, while $2 \%$ were indifferent.
\end{abstract}

Keywords: ecological footprint, environmental sustainability

\section{Introduction}

With the continuous growth of the world's population, advancement in technology and development of economies, there is a concomitant increase in the utilization of the earth's resources. However, these resources are finite hence one of the major challenges confronting us in the $21^{\text {st }}$ century is environmental sustainability. The present generation must ensure that while it meets its own needs, the ability of the future generations to meet their needs is not compromised.

Studies have shown that humans are consuming natural resources at a rate much faster than the Earth can regenerate (Farber, 2012, [1] Ruzevicius, 2011, [2] Best, 2008, [3] Hurley et al., 2007, [4] Moffatt, 2000, [5] Onisto et al., 1998) [6]. As such, the earth is overused and overburdened. It unburdens and releases stress through the many devastating environmental changes experienced globally. Climate change like off- season prolonged droughts occur in some countries while simultaneously other parts of the world are submerged in water. Calamities like volcanic eruptions, earthquakes and tsunamis happen more frequently in various parts of the globe nowadays, whereas before they were rare events. No country has been spared of these environmental disturbances.

\subsection{Footprint and Environmental Sustainability}

An ecological footprint is an indicator of the balance of the demand on the earth's resources and the ability of the earth to supply these resources. It is measured in global hectares (gha), indicating the productive land and sea areas needed to provide the resources a population consumes and to assimilate the associated waste. The footprint is broken down into four consumption categories: carbon, food, housing, goods and services 
(Center for Sustainable Economy).The concept of ecological footprint was developed by Wackernagel and Reese (1996) [7] to represent natural resource consumption associated with human activity.

The life styles of the individuals in a country with a given level of economic development influences primarily the ecological footprint of the nation. Making people aware of the impact of their lifestyles on ecological footprints is one way to enable them to realize their responsibility in helping to mitigate the severity of the problem of attaining environmental sustainability. An ecological footprint is a useful indicator of per capita consumption of resources. Using this assessment, it is possible to determine the number of earths needed to support humanity with individuals following their lifestyles.

In a comprehensive review of the perceptions and methods around the ecological footprint indicators, ecological footprint is seen as a strong communication tool. Its main strengths are: ability to condense the size of human pressure on the different types of productivity into a single figure, possibility to provide some sense of overconsumption and opportunity to communicate results to a wide audience (Wiedmann and Barrett, 2010) [8].

Ecological footprint analysis has attracted attention and is widely accepted for its clear concept and the simple calculations it involves. It can also be applied at various scales: individual, school, community, local, regional, national or world level. It has been used to: examine the effect of climate change on an urban university's ecological footprint (Banai and Theis, 2011) [9]; survey level of awareness of ecological footprint as an indicator of sustainable development among business representatives and specialists in government organizations responsible for sustainable development policies of Lithuania (Ruzevicius, 2011) [2]; serve as an innovative educational tool for advancing environmental sustainability in an Israeli public school (Gottlieb et al., 2012) [10] ; assess environmental awareness among higher primary school teachers in India (Larijani, 2010) [11]; evaluate and regulate sustainable development in selected cities in China ( Xiaodong et al., 2005) [12]; monitor impacts from natural resource use in the European Union's thematic strategy on the sustainable use of natural resources (Best, 2008) [3]; analyze urban development in a residential estate in Melbourne (Hurley et al., 2007) [4]; evaluate sustainability of consumption patterns utilizing ecological footprint questionnaire and remote sensing image analysis of ecological capacity(Chang and Xiong, 2004) [21]; and challenge students in each lifestyle category to set goals for themselves based on their initial footprints and then comparing these initial footprints with their footprints after implementing the goals set for an agreed upon time interval (Turner,2010) [13].

Despite the acknowledged utility of ecological footprint analysis as an environmental sustainability indicator, it has some limitations. It is stated that its simplicity does not permit it to be used as a single indicator to guide policy formulation on sustainable development. The ecological footprint needs to be used together with a basket of other indicators namely: environmentally-weighted material consumption (EMC), human appropriation of net primary production (HANPP) and land and ecosystem accounts (LEAC) to be most effective, meaningful and robust at aggregate levels (national and above) (Wiedmann and Barrett, 2010, [8] Best et al., 2008) [3]. Besides ecological footprint is a static indicator. It measures environmental sustainability at a particular point in time. Also, it does not include toxic waste production and assimilation (Bunker, 2005) [14].

\subsection{Business and Environmental Sustainability}

Cognizant of the impact of global business activities on environmental sustainability, this sector has taken initiatives to reduce its damaging effects through consideration of nature as a stakeholder in the management of enterprises. Global economy and global ecology are interdependent. The planet imposes the boundary upon which efficiency and 
abundance are understood. There is an urgent need to find an environmentally sustainable path into the $21^{\text {st }}$ century. Ignoring this challenge is unthinkable (Gibson, 2012) [15].

An objection to this challenge is that the concept of sustainability may not capture all that is valuable in the environment. Sustainability calculations reduce to cost benefit analysis, assigning values that is subject to interpretation. Some resources are priceless. However, use of sustainability as a focus of concern is significant since it provides us with a more tenable and quantifiable standard for the development of measures such as the UN sustainability indicators (Gibson, 2012) [15].

Sustainable development includes a commitment to advancing human well-being within the limits of the earth's resources. Human development index (HDI) is used as an indicator of development and ecological footprint is used as an indicator of human demand on the earth's resources. An HDI of noless than 0.8 and a per capita of ecological footprint which is less than the bio-capacity per person will representminimum requirements for replicable sustainable development (Dicksai, 2012) [16].

Albino et al., (2012) [17] reported that to face the environmental sustainability challenge a growing number of companies are shifting (or planning to shift) toward sustainability -oriented business models, adopting environmental strategies and developing green products. Four environment strategic approaches were identified towards green product development: improvement of material eco-efficiency (reduction of resources used to produce unitary output),improvement of energy efficiency (increased energy savings and use of renewable resources), implementation of green management (systematic and comprehensive mechanism to improve environmental business performance inside a company) and implementation of green supply chain management (extend environmental measures to whole supply chain).

This study was done to measure and compare ecological footprints of students from three countries with different levels of economic development and to generate their awareness of environmental stability through their ecological footprints. The youth, like the student respondents in this study, will be the potential leaders and decision makers in the future. Furthermore, schools are tasked not only with the cognitive and psychomotor development of the students but also of their affective aspect (Gottlieb2012, [10] Ryu and Brody, 2006) [18].

\section{Method}

College students from Canada (15), Philippines (78) and Thailand (120) were requested to answer an online ecological quiz (myfootprint.org). The number of earths needed to support their lifestyles. The ecological footprint data in global hectares (gha) includes four consumption areas namely: carbon, food, housing, goods and services. The students from the Philippines were taking BS Accountancy, BS Business Administration, Education and Communication Arts. Those from Thailand were enrolled in Logistics and Management of Information Systems while those from Canada were enrolled in Management Information Systems. The ecological footprint data was subjected to ANOVA and subsequent post hoc multiple comparisons if the ANOVA results are significant.

\section{Results and Discussion}

\subsection{Demographic Profile of the Respondents}

Thirty \% (30\%) of the students from the Philippines were male and $70 \%$ were female. They belong to age 17-25 years old. Among the Thai students $43 \%$ were male and 57\% were female. Their ages ranged mostly from 20 - 25 years old and 1 was 33 years old and another was 44years old. The ages of the students in the Canadian group ranged from 22- 
33years old. One of the respondents did not indicate his age. Sixty $\%$ of them were enrolled in IT, 20\% in Business and 7\% each in Management and Administration.

\subsection{Ecological Footprint Results}

Tables1, 2 and 3 present the descriptive statistics of the ecological footprints of the selected students from Canada, Thailand and Philippines. As expected the values are lowest for the Filipinos and highest for the Canadian students owing to the higher economic levels, state of technology development in the country and disposable income of the latter group.

ANOVA of the ecological footprints of the students from the three countries gave significant differences between their mean consumption of natural resources and number of earths to support their lifestyles. Their carbon, food, housing, goods and services, crop land, pasture land, marine and fisheries and forestland footprints were all significant at .05. All post -hoc multiple comparisons between any two groups among the three groups of respondents were also all significant at .05 except for the number of earths and carbon footprint of Thai and Canadian students (Tables 4 and 5).

Figures 1, 2 and 3 illustrate the distribution of the carbon, food, housing, goods and services consumption of the three groups of students. The greatest \% of consumption among Filipino students is food. Having limited income to spend, food is given the highest priority as a basic need(GDP in 2012 was2,345 million USD). Since most of them use public transportation to commute to school and elsewhere, carbon emission is low compared to the other two groups. Many students live with their families who also support their education; hence their housing needs are also low. Since the Philippines is archipelagic, most food resources come from marine and fisheries (Figure 4).

Thailand is acknowledged to be a fast-growing economy in Asia. It registered a full year growth of $6.6 \%$.Its GDP in 2012 was 5,395 MILLION USD. Its students have the propensity to spend more for goods and services. Since its technology is continuously developing, it consumes more energy and therefore produces a higher carbon footprint compared to the Philippines and even higher than that of Canada. Its pasture land and marine and fisheries provide almost the same amounts of raw materials to meet the basic needs of the people (Figure 5).

Although the Canadian students required the highest mean number of earths and ecological footprints, their bio-capacity is also the highest, meaning their resources are capable of producing more than the needed materials for a sustainable environment. Canada has more unused lands and its major sources are its forests (Figure 6).Its 2012 GDP was 51,600 million USD. According to the latest available data on ecological footprint and bio-capacity, Canada has a reserve of 7.9 gha per capita while the Philippines have a deficit of 0.7 gha. Likewise, Thailand has a deficit of 1.2 gha (National Footprint Accounts, 2010).

It is intuitive that a country's ecological footprint should correlate with its Gross Domestic Product (GDP), since raising GDP involves placing more stress on natural resources for both production and waste disposal. To reduce a country's footprint while maintaining or increasing its GDP is going to be quite difficult. Indefinite economic growth is not a prospective solution to environmental problems ((Bagliani,Bravo \&Dalmazzone, 2006) [19]. It is apparent that the best and most effective way to lower our footprint is to reduce our demand on the earth's resources in addition to reusing and recycling most of our natural resources. In the end, we all share the same planet. It is up to us whether we act immediately with resolve to help minimize further environmental degradation or simply look at ecological footprint as an attention-getting device. 
Table 1. Descriptive Statistics of Ecological Footprints of Selected Filipino Students

\begin{tabular}{|l|l|l|l|l|}
\hline & $\begin{array}{l}\text { Minimum } \\
\text { (gha) }\end{array}$ & $\begin{array}{l}\text { Maximum } \\
\text { (gha) }\end{array}$ & $\begin{array}{l}\text { Mean } \\
\text { (gha) }\end{array}$ & $\begin{array}{l}\text { Standard } \\
\text { Deviation(gha) }\end{array}$ \\
\hline 1. Number of earths & 0.29 & 1.50 & 0.45 & 0.17 \\
\hline 2. Carbon footprint & 0.51 & 7.30 & 1.15 & 1.25 \\
\hline 3. Food footprint & 1.54 & 7.13 & 3.91 & 0.82 \\
\hline 4. Housing footprint & 0.17 & 2.79 & 0.63 & .31 \\
\hline $\begin{array}{l}\text { 5. Good \& services } \\
\text { footprint }\end{array}$ & 0.10 & 6.78 & 1.09 & 0.78 \\
\hline 6. Cropland & 0.32 & 4.56 & 0.97 & 0.61 \\
\hline 7. Pastureland & 0.57 & 10.50 & 1.42 & 1.46 \\
\hline 8. Marine \& fisheries & 1.18 & 11.35 & 3.40 & 1.45 \\
\hline 9. Forest land & 0.80 & 16.02 & 2.03 & 2.17 \\
\hline
\end{tabular}

Table 2. Statistics of Ecological Footprint of Selected Thai Students

\begin{tabular}{|l|l|l|l|l|}
\hline & $\begin{array}{l}\text { Minimum } \\
\text { (gha) }\end{array}$ & $\begin{array}{l}\text { Maximum } \\
\text { (gha) }\end{array}$ & $\begin{array}{l}\text { Mean } \\
\text { (gha) }\end{array}$ & $\begin{array}{l}\text { Standard } \\
\text { Deviation(gha) }\end{array}$ \\
\hline 1 Number of earths & 0.61 & 55.10 & 2.85 & 7.35 \\
\hline 2 Carbon footprint & 1.10 & 55.39 & 7.07 & 8.45 \\
\hline 3. Food footprint & 1.31 & 21.10 & 6.86 & 3.50 \\
\hline 4. Housing footprint & 0.82 & 31.20 & 3.12 & 3.67 \\
\hline 5. Good \& services footprint & 2.40 & 44.10 & 8.67 & 5.77 \\
\hline 6. Cropland & 1.00 & 66.66 & 4.19 & 6.49 \\
\hline 7.Pastureland & 1.00 & 77.10 & 6.50 & 8.00 \\
\hline 8.Marine \& fisheries & 1.00 & 88.32 & 7.15 & 8.73 \\
\hline 9.Forest land & 1.00 & 88.32 & 8.61 & 9.94 \\
\hline
\end{tabular}

Table 3. Descriptive Statistics of Ecological Footprint of Selected Canadian Students

\begin{tabular}{|l|l|l|l|l|}
\hline & $\begin{array}{l}\text { Minimum } \\
\text { (gha) }\end{array}$ & $\begin{array}{l}\text { Maximum } \\
\text { (gha) }\end{array}$ & $\begin{array}{l}\text { Mean } \\
\text { (gha) }\end{array}$ & $\begin{array}{l}\text { Standard } \\
\text { Deviation(gha) }\end{array}$ \\
\hline 1.Number of earths & 1.81 & 8.49 & 4.52 & 1.47 \\
\hline 2.Carbon footprint & 0.52 & 30.49 & 11.00 & 7.11 \\
\hline 3. Food footprint & 6.74 & 40.60 & 28.94 & 9.13 \\
\hline 4. Housing footprint & 2.00 & 19.81 & 10.46 & 5.02 \\
\hline $\begin{array}{l}\text { 5. Goods \& services } \\
\text { footprint }\end{array}$ & 4.67 & 42.40 & 19.59 & 8.80 \\
\hline 6.Cropland & 0.12 & 15.81 & 8.24 & 3.43 \\
\hline 7.Pasture land & 0.27 & 36.75 & 18.60 & 8.25 \\
\hline 8.Marine \& fisheries & 0.19 & 26.06 & 13.04 & 5.74 \\
\hline 9.Forest land & 0.41 & 54.68 & 26.35 & 12.00 \\
\hline
\end{tabular}


Table 4. Summary ANOVA of Ecological Footprints of Selected Students from Three Countries

\begin{tabular}{|c|c|c|c|}
\hline & $\begin{array}{l}\text { F (calculated } \\
\text { value) }\end{array}$ & $\begin{array}{l}\text { Significance, } \\
\text { two tailed }, \alpha= \\
.05\end{array}$ & Interpretation \\
\hline 1. \# of earths & 6.067 & 0.003 & significant \\
\hline 2. Carbon footprint & 24.940 & 0.000 & significant \\
\hline 3. Food footprint & 311.139 & 0.000 & significant \\
\hline 4. Housing footprint & 68.508 & 0.000 & significant \\
\hline $\begin{array}{l}\text { 5. Goods \& services } \\
\text { footprint }\end{array}$ & 112.430 & 0.000 & significant \\
\hline 6. Cropland & 17.978 & 0.000 & significant \\
\hline 7. Pastureland & 48.373 & 0.000 & significant \\
\hline 8. Marine\& fisheries & 15.452 & 0.000 & significant \\
\hline 9. Forestland & 58.222 & 0.000 & significant \\
\hline
\end{tabular}

Table 5. Summary of Post Hoc Multiple Comparisons

\begin{tabular}{|c|c|c|}
\hline \multicolumn{3}{|c|}{$\#$ of earths footprint } \\
\hline Groups compare & Calculated probability & Significance,two-tailed ,05 \\
\hline Filipinos and Thai & .013 & significant \\
\hline Filipinos and Canadian & .033 & significant \\
\hline Thai and Canadian & .540 & not significant \\
\hline \multicolumn{3}{|c|}{ Carbon footprint } \\
\hline Filipinos and Thai & .000 & significant \\
\hline Filipinos and Canadian & .000 & significant \\
\hline Thai and Canadian & .099 & not significant \\
\hline \multicolumn{3}{|c|}{ Food footprint } \\
\hline Filipinos and Thai & .000 & significant \\
\hline Filipinos and Canadian & .000 & significant \\
\hline Thai and Canadian & .000 & significant \\
\hline \multicolumn{3}{|c|}{ Housing footprint } \\
\hline Filipinos and Thai & .000 & significant \\
\hline Filipinos and Canadian & .000 & significant \\
\hline Thai and Canadian & .000 & significant \\
\hline \multicolumn{3}{|c|}{ Goods and Services footprint } \\
\hline Filipinos and Thai & .000 & significant \\
\hline Filipinos and Canadian & .000 & significant \\
\hline Thai and Canadian & .000 & significant \\
\hline \multicolumn{3}{|c|}{ Cropland footprint } \\
\hline Filipinos and Thai & .000 & significant \\
\hline Filipinos and Canadian & .000 & significant \\
\hline Thai and Canadian & .013 & significant \\
\hline \multicolumn{3}{|c|}{ Pastureland footprint } \\
\hline Filipinos and Thai & .000 & significant \\
\hline Filipinos and Canadian & .000 & significant \\
\hline Thai and Canadian & .000 & significant \\
\hline
\end{tabular}




\begin{tabular}{|l|c|l|}
\hline Filipinos and Thai & .001 & significant \\
\hline Filipinos and Canadian & .000 & significant \\
\hline Thai and Canadian & .007 & significant \\
\hline \multicolumn{3}{|c|}{ Forestland footprint } \\
\hline Filipinos and Thai & .000 & significant \\
\hline Filipinos and Canadian & .000 & significant \\
\hline Thai and Canadian & .000 & significant \\
\hline
\end{tabular}

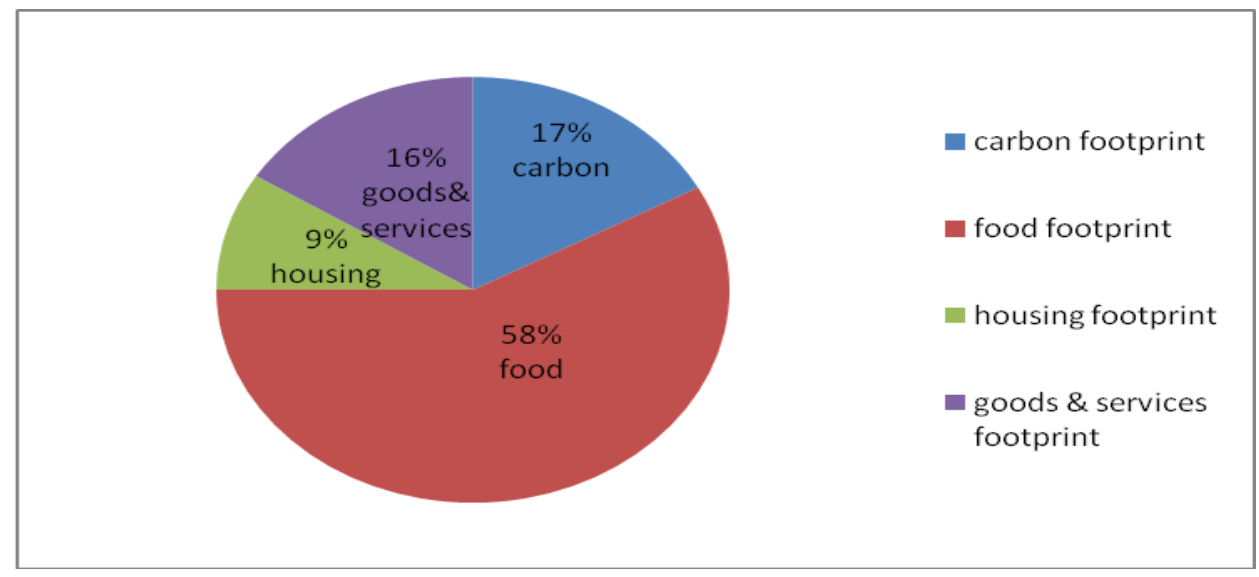

Figure 1. Ecological Footprints of Selected Filipino Students

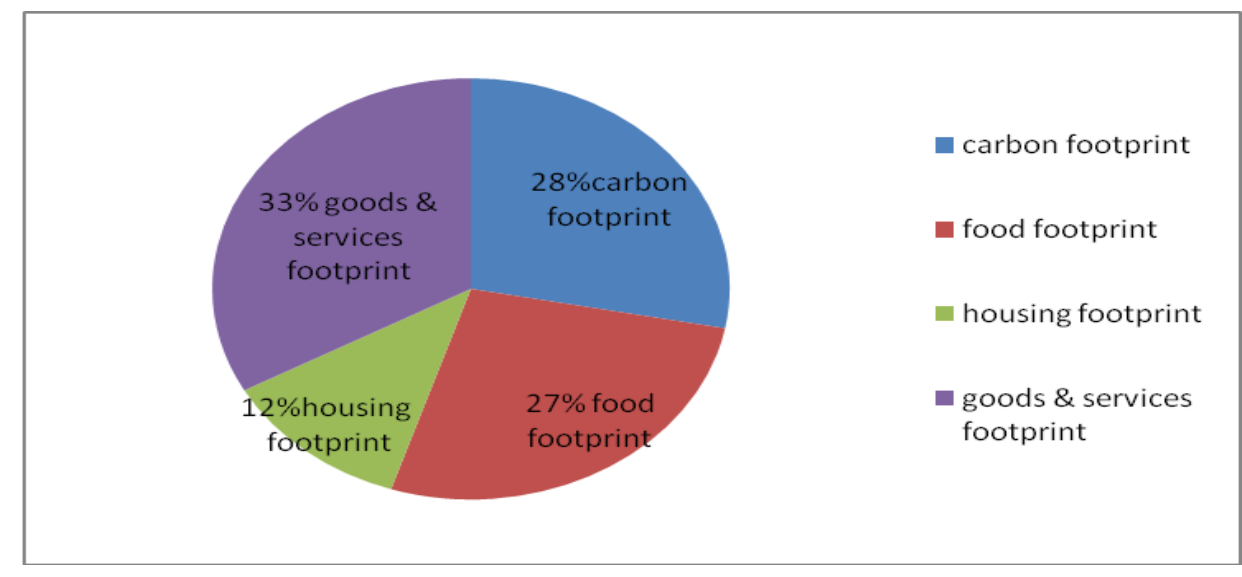

Figure 2. Ecological Footprints of Selected Thai Students

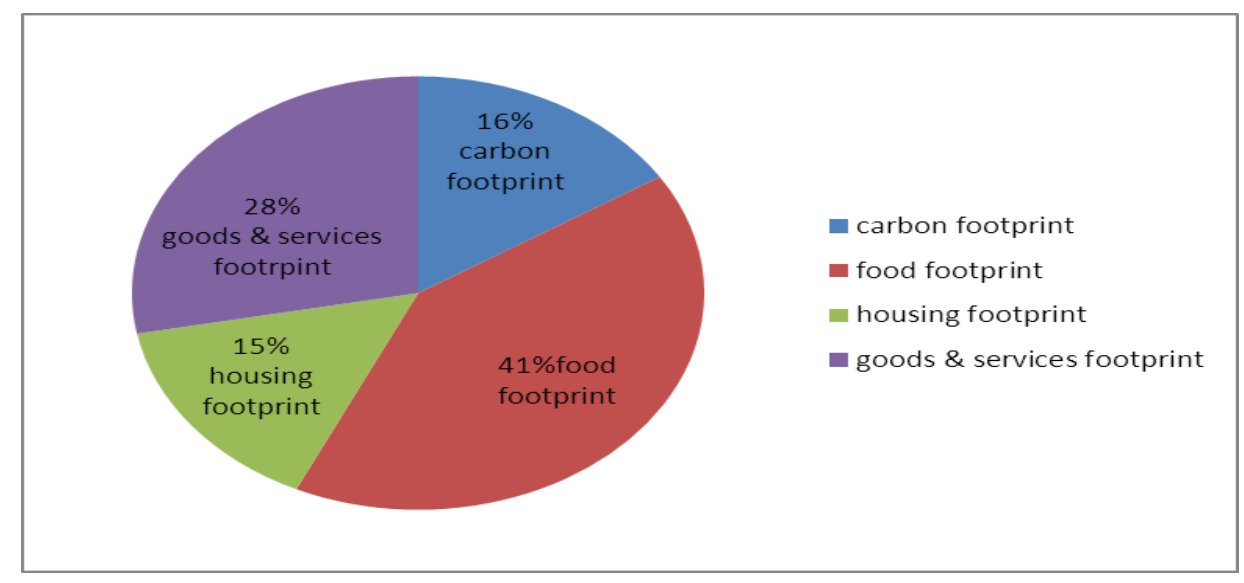

Figure 3. Ecological Footprints of Selected Canadian Students 


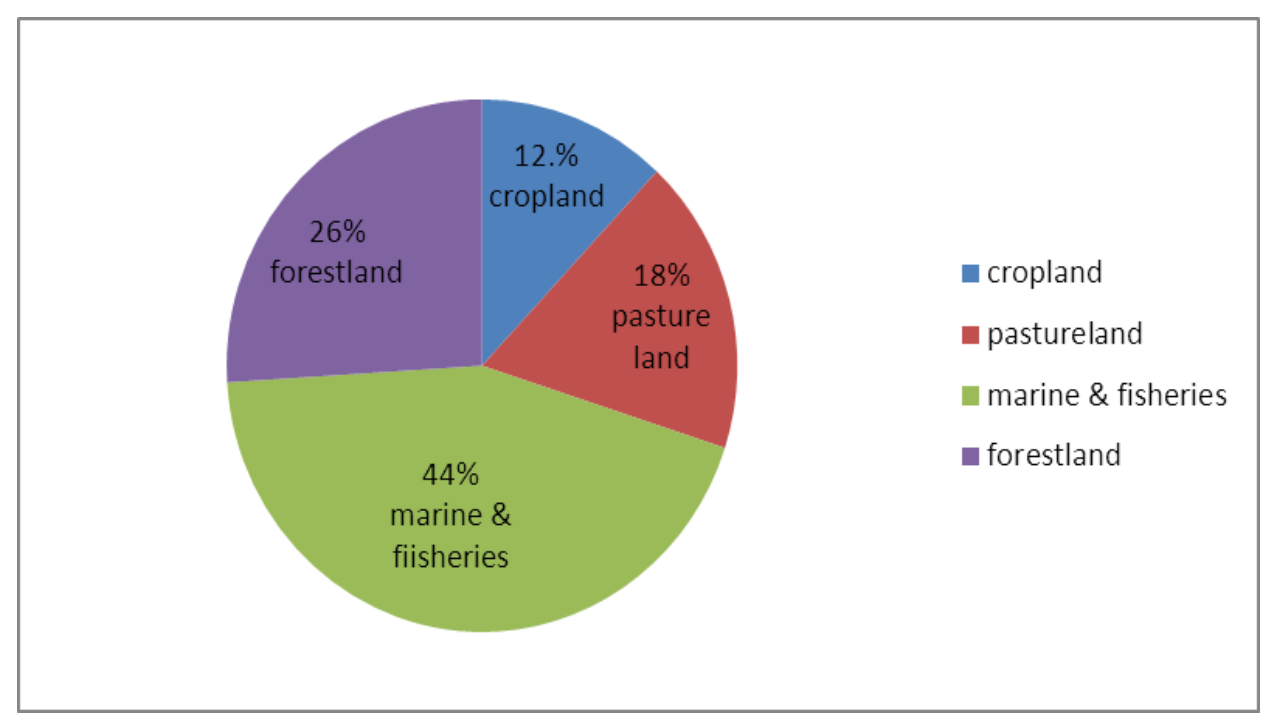

Figure 4. Sources of Ecological Footprints of Selected Filipino Students

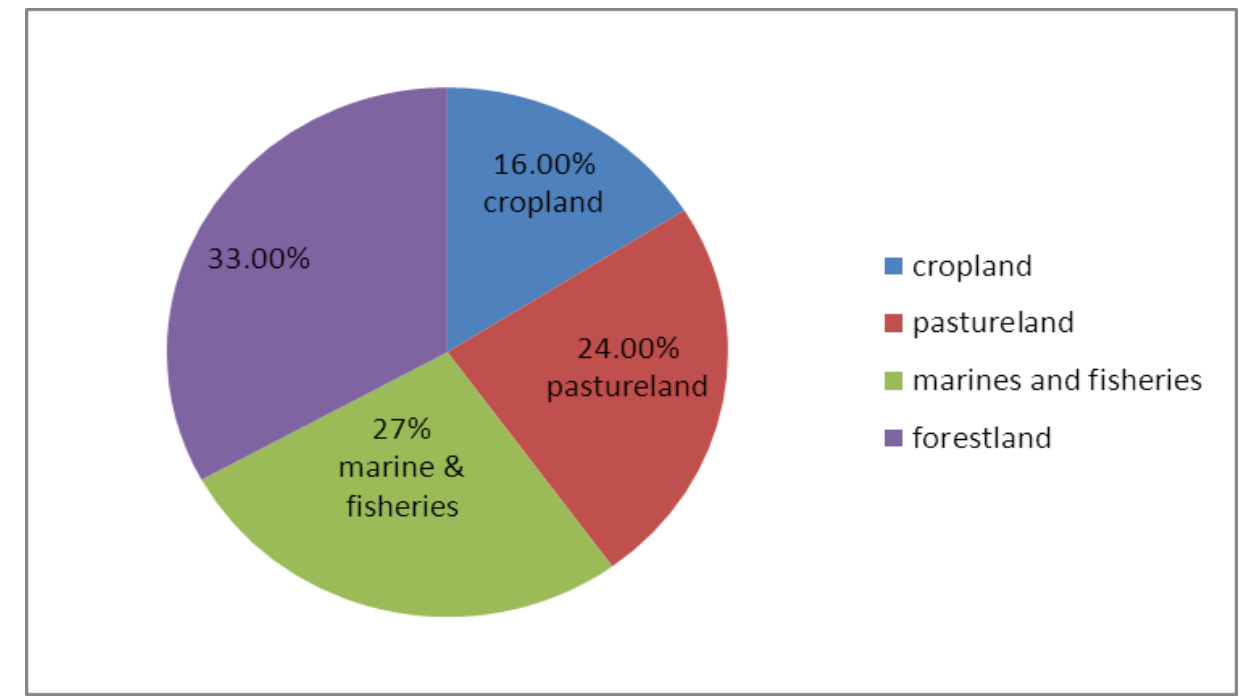

Figure 5. Sources of Ecological Footprints of Selected Thai Students

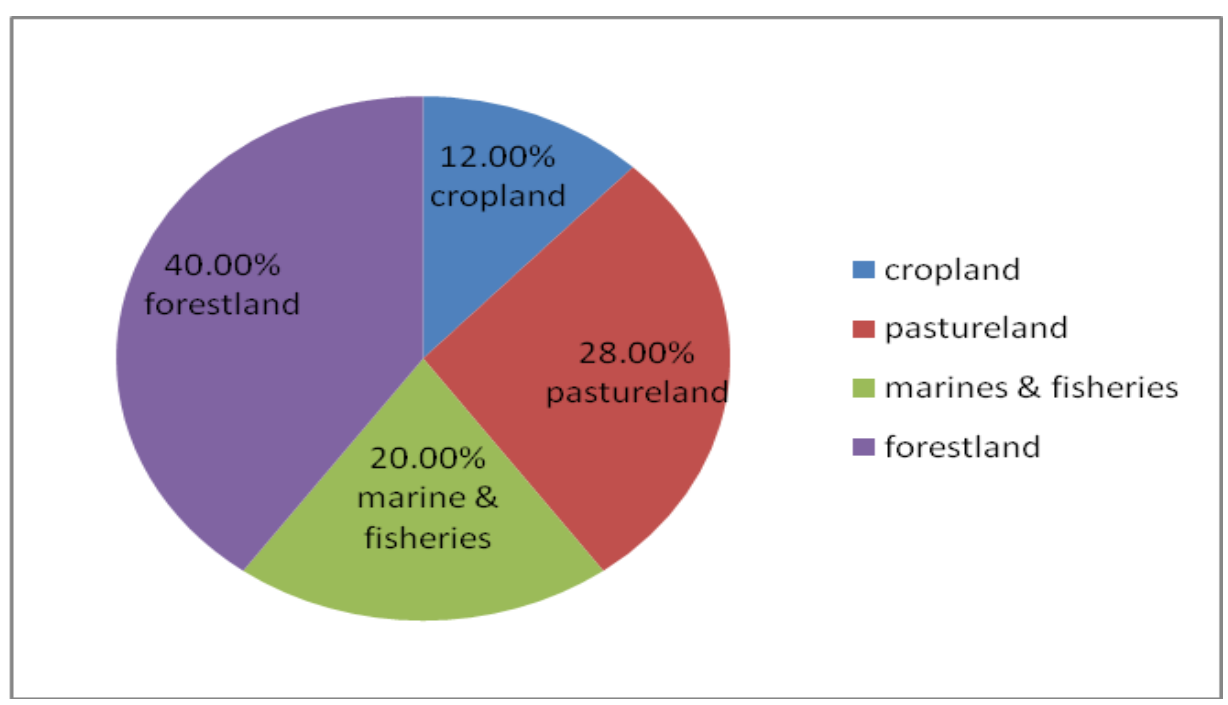

Figure 6. Sources of Ecological Footprints of Selected Canadian Students 


\subsection{Feelings of the Respondents about Their Ecological Footprint Results}

When the students were asked about their feelings after finding out the results of their ecological footprints, $40 \%$ of the Thai respondents felt glad they were helping ensure ecological sustainability for the future, $27 \%$ felt relieved they were living sustainable lifestyles, $16 \%$ felt embarrassed they were consuming more resources than what the earth can produce, $14 \%$ felt concerned but acknowledged they cannot change their lifestyles, 2 $\%$ were indifferent and $1 \%$ did not reply. It is encouraging to know the students have realized their share in contributing to environmental sustainability although some admitted they cannot change their lifestyles despite being concerned about the welfare of the environment. In a related research, people who found out about their non-satisfactory footprints reacted to change their views about environmental sustainability to match their results instead of committing to improve on their non-sustainable lifestyles (McCune,2012)[20].Some of the Canadian students opted to give their comments instead. One mentioned it is up for the business companies to produce green products for people's consumption so further environmental damage is minimized. All the Filipino students were glad and relieved that their ecological footprints contribute to a sustainable environment.

\section{Conclusion}

Significant differences were observed between the ecological footprints of the selected students from the Philippines, Canada and Thailand. They also showed significant differences in the sources of these footprints. Their responses after obtaining their footprint results indicate their concern for a sustainable environment which may be sufficient to initiate improvement in our environment.

\section{References}

[1] D. Farber, "Vanderbilt Law Review", vol. 65, no. 6, (2012).

[2] J. Ruzevicius, Home 6, 1, (2011).

[3] A. Best Analysis of the potential of the ecological footprint and related assessment tools for use in the EU's thematic strategy on the sustainable use of natural resources, Report to the European Commission DG Environment, (2008).

[4] J Hurley, R. Home and T. Grant, "Ecological footprint as an assessment tool for urban development", Paper Presented at the Australian Cities Conference, University of South Australia, (2007).

[5] I. Moffatt, "Ecological Economics", vol. 32, (2000).

[6] L. J. Onisto, E. Krause and M. Wackernagel, "Using the concept of appropriated carrying capacity for measuring sustainability", Center for Sustainable Studies and City of Toronto, (1998).

[7] M. Wackernagel and W. E. Reese, "Our Ecological Footprint Reducing Human Impact on Earth", New Society Publishers Gabriola Island, B.C., (1996).

[8] T. Wiedmann and J. Barrett, Sustainability 2, (2010).

[9] C. K. Banai and T. L. Theis, Ecological Indicators 11, (2011).

[10] D. Gottlieb, E. V. Gadot, A. Haim and M. Kissinger, Journal of Development, vol. 32, (2012).

[11] M. Larijani, Journal of Home Ecology, vol. 31, no. 2, (2010).

[12] K. Xiao-dong, Ll. Huang-jun, W. Qing, Y. LinandXue and Heu-feng, "Northeastern Polytechnic Institute", Institute of Resources and Environmental Information Engineering Resources and Ecological Economic Research Center, 10 p (2005).

[13] T. Turner, The Middle Years 84-88, (2010).

[14] G. Bunker, "Ecological Footprint Analysis: Background and Rationale", (2005).

[15] K. Gibson, Journal of Business Ethics 109, (2012).

[16] R. Dicksai, The Futurist 48-54 (2012).

[17] V. Albino, A. V. Balice, R. M. Dangelico and F. A. Iacobone, International Journal of Management, vol. 29, no. 2, (2012).

[18] H. C. Ryu and S. D. Brody, Journal of Sustainability in Higher Education, vol. 7, no. 2, (2006)

[19] M. Bagliani, G. Bravo and S. Dalmazzone, Interdisciplinary Research Institute on Sustainability, (2006).

[20] M. McCune, McCune .com e-newsletter, (2012).

[21] B. Chang and L Xiong, "Ecological footprint research based on RS and GIS in HexiCorridor", China. Geoscience and Remote Sensing Symposium IGARSS 7, (2004), pp. 4643-4646. 
International Journal of Education and Learning Vol.3, No.2 (2014) 